\title{
MODEL MATEMATYCZNY KARTEZJAŃSKIEGO MANIPULATORA WEASNEJ KONSTRUKCJI
}

\begin{abstract}
W referacie zaprezentowano opis matematyczny robota manipulacyjnego własnej konstrukcji. Robot o strukturze kinematycznej kartezjańskiej posiada trzy stopnie swobody. Sformułowano opis matematyczny kinematyki i dynamiki manipulatora. Do opisu kinematyki zastosowano notację Denavita-Hartenberga. Dynamiczne równania ruchu manipulatora uzyskano z zastosowaniem równań Lagrange'a drugiego rodzaju. W opisie dynamiki manipulatora uwzględniono dynamikę napędów. Dokonano analizy właściwości strukturalnych modelu matematycznego, które są wykorzystywane w syntezie algorytmów sterowania manipulatorami.
\end{abstract}

Słowa kluczowe: manipulator kartezjański, model manipulatora, kinematyka manipulatora, dynamika manipulatora, właściwości strukturalne modelu

\section{Wprowadzenie}

Do jednej z najpopularniejszych odmian manipulatorów należą manipulatory o strukturze kinematycznej kartezjańskiej. Powodem tego jest szeroka oferta rynku automatyki i robotyki w zakresie modułowych rozwiązań, zapewniających elastyczność podczas projektowania i konstruowania robotów do specjalizowanych zadań. Istotnymi zaletami manipulatorów kartezjańskich są: łatwość osiągnięcia dużej sztywności konstrukcji, prostota opisu kinematyki i dynamiki, łatwość wyznaczania przestrzeni roboczej i planowania w niej zadań. Prace badawcze dotyczące manipulatorów kartezjańskich prowadzone są głównie w zakresie budowy modeli matematycznych, w tym modeli uwzględniających podatność konstrukcji [4, 6] oraz sterowania manipulatorami kartezjańskimi $\mathrm{z}$ uwzględnieniem modeli matematycznych $\mathrm{w}$ prawie sterowania $[3,9]$.W praktyce przemysłowej stosowane są $\mathrm{w}$ większości manipulatory o stosunkowo prostej konstrukcji, dużej sztywności i dokładności pozycjonowania. Odpowiednia dokładność może być zapewniona przez zastosowanie śrub kulowych w układzie przeniesienia napędu [5].

W referacie zaprezentowano opis matematyczny robota manipulacyjnego własnej konstrukcji. Robot o strukturze kinematycznej kartezjańskiej posiada

\footnotetext{
1 Autor do korespondencji/corresponding author: Piotr Gierlak, Politechnika Rzeszowska, al. Powst. Warszawy 12, 35-959 Rzeszów, tel.: (17) 8651854, e-mail: pgierlak@prz.edu.pl
} 
trzy stopnie swobody. Jest przeznaczony m.in. do badań dotyczących robotyzacji procesów obróbki mechanicznej części maszyn. Wyposażony jest w tzw. moduły liniowe składające się z prowadnic i wózków napędzanych silnikami prądu stałego z wykorzystaniem przekładni zębatych oraz śrub kulowych. Manipulator wyposażony jest w enkodery zamocowane na wałach silników napędowych, czujnik siły umieszczony w końcówce i głowicę z napędem pneumatycznym, w której znajduje się narzędzie skrawające, np. pilnik, frez, itp.

Ze względu na fakt, że prezentowany robot nie jest produktem komercyjnym, lecz układem zbudowanym według własnego projektu autora, konieczne jest zaprojektowanie i wykonanie licznych modułów programowych służących do symulacji oraz programowania robota i sterowania nim. Celem pracy jest, zatem sformułowanie modelu matematycznego manipulatora, który posłuży do syntezy algorytmów sterowania manipulatorem. Model matematyczny jest również tworzony z myślą o zastosowaniu go w prawie sterowania manipulatorem. $\mathrm{W}$ związku z tym istotne jest zbadanie właściwości strukturalnych modelu matematycznego manipulatora. W rozdziale 2 przyjęto schemat modułów napędowych i zaprezentowano opis ich dynamiki. W rozdziale 3 przyjęto model manipulatora i przedstawiono równania kinematyki i dynamiki obiektu z uwzględnieniem dynamiki modułów napędowych. Kolejny rozdział dotyczy analizy właściwości strukturalnych modelu matematycznego. W ostatnim rozdziale dokonano podsumowania pracy.

\section{Dynamika modułów napędowych}

Manipulator zbudowany jest $\mathrm{z}$ elementów modułowych, którymi są napędy liniowe. Moduł napędowy liniowy składa się z prowadnicy z wózkiem, którego ruch jest wymuszany ruchem obrotowym śruby kulowej napędzanej silnikiem prądu stałego z przekładnią zębatą. Moduł liniowy schematycznie przedstawiono na rysunku 1 . Równanie ruchu wirnika silnika zapisano zgodnie z oznaczeniami na rysunku $1 \mathrm{w}$ postaci $[1,7]$ :

$$
J_{S} \ddot{q}_{S}+B_{S} \dot{q}_{S}+M_{\mathbf{I}}=K_{m} i_{W}
$$

gdzie: $M_{1}$ - moment obciążenia,

$K_{m}$ - stała momentu,

$i_{W}$ - prąd wirnika, (pozostałe oznaczenia objaśniono w podpisie rys. 1).

Równanie ruchu śruby kulowej z uwzględnieniem elementów przekładni to:

$$
\left(J_{P R}+J_{S R}\right) \ddot{q}_{S R}+M_{O S R}+i_{S R} P=M_{2}
$$

gdzie: $M_{O} S_{R}-$ moment oporów ruchu śruby,

$i_{S R}=\dot{q} / \dot{q}_{S R}-$ przełożenie przekładni śrubowej, 
$M_{2}$ - moment napędzający od strony silnika.

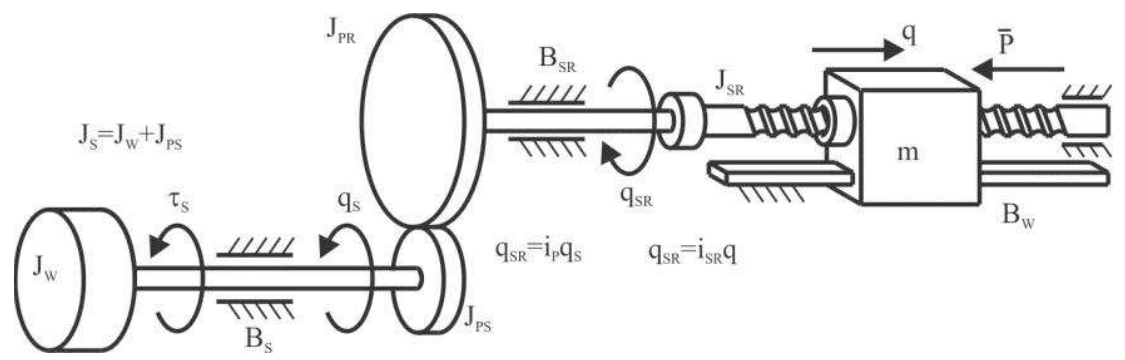

Rys. 1. Schemat modułu napędowego robota: $J_{W^{-}}$masowy moment bezwładności wirnika silnika, $J_{P S}$ - masowy moment bezwładności koła przekładni od strony silnika, $J_{P R}$ - masowy moment bezwładności koła przekładni od strony wózka, $J_{S}$ - masowy moment bezwładności modułu napędowego, $J_{S R}$ - masowy moment bezwładności śruby, $m$ - masa wózka oraz elementów znajdujących się na nim, $\tau_{S}=K_{m} i_{W}-$ moment generowany przez silnik, $B_{S}$ - współczynnik oporów ruchu wirnika, $B_{S R}$ - współczynnik oporów ruchu śruby i wału przekładni, $B_{W}$ - współczynnik oporów ruchu wózka, $q_{S}-$ kąt obrotu wirnika silnika, $q S R$ - kąt obrotu śruby, $q$ - przemieszczenie wózka, $i_{P}-$ przełożenie przekładni zębatej, isR - przełożenie przekładni śrubowej, $P$ - siła zewnętrzna

Fig. 1. Scheme of robot's drive: $J_{W-}$ mass moment of inertia of the motor shaft, $J_{P S}-$ mass moment of inertia of the gear wheel from the side of drive, $J_{P R}$ - mass moment of inertia of the gear wheel from the side of truck, $J_{S}$ - mass moment of inertia of the drive, $J_{S R}$ - mass moment of inertia of the screw, $m$ - mass of the truck and items on it, $\tau_{S}=K_{m} i_{W}$ - the torque generated by the drive, $B_{S}$ - coefficient of shaft motion resistance, $B_{S R}$ - coefficient of motion resistance of screw gear shaft, $B_{W}$ - coefficient of truck motion resistance, $q_{S}$-angle of rotation of the motor shaft, $q_{S R}$ - angle of rotation of the screw, $q$-displacement of the truck, $i_{P}$ - gear ratio, $i_{S R}$ - helical gear ratio, $P$ external force

Zakładając równość mocy:

$$
M_{1} \dot{\boldsymbol{q}}_{S}=M_{2} \dot{q}_{S R}
$$

i przełożenie:

$$
\dot{q}_{S R}=i_{P} \dot{q}_{S}
$$

równanie (1) zapisano w następującej postaci:

$$
\left[J_{S}+\left(J_{P R}+J_{S R}\right) i_{P}^{2}\right] \ddot{q}_{S}+B_{S} \dot{q}_{S}+i_{P} M_{O S R}=K_{m} i_{W}-i_{P} i_{S R} P
$$

i uzyskano opis dynamiki modułu napędowego w funkcji kinematycznych parametrów ruchu wału silnika. Podobnie można zapisać równania ruchu pozostałych napędów i przedstawić je wszystkie w zwartej formie macierzowej: 


$$
\mathbf{J} \ddot{\mathbf{q}}_{S}+\mathbf{B} \dot{\mathbf{q}}_{S}+\mathbf{F}_{S R}=\mathbf{K} \dot{i}_{W}-\mathbf{i P}
$$

gdzie: $\mathbf{J}=\operatorname{diag}\left\{J_{1}, J_{2}, J_{3}\right\}-$ macierz bezwładności, $J_{j}=J_{S j}+\left(J_{P R j}+J_{S R j}\right) i_{P j}{ }^{2}, j=1,2,3$,

$\mathbf{q}_{S}=\left[q_{S 1}, q_{S 2}, q_{S 3}\right]^{T}-$ wektor kątów obrotu wirników silników,

$\mathbf{B}=\operatorname{diag}\left\{B_{S 1}, B_{S 2}, B_{S 3}\right\}-$ macierz oporów ruchu wirników silników,

$\mathbf{K}=\operatorname{diag}\left\{K_{m 1}, K_{m 2}, K_{m 3}\right\}$ - macierz stałych momentowych silników,

$\mathbf{i}_{W}=\left[i_{W 1}, i_{W 2}, i_{W 3}\right]^{T}-$ wektor prądów wirników,

$\mathbf{i}=\operatorname{diag}\left\{i_{P 1} i_{S R 1}, i_{P 2} i_{S R 2}, i_{P 3} i_{S R}\right\}-$ macierz przełożeń przekładni,

$\mathbf{P}=\left[P_{1}, P_{2}, P_{3}\right]^{T}-$ wektor sił zewnętrznych,

$\mathbf{F}_{S R}=\left[i_{P 1} M_{O S R 1}, i_{P 2} M_{O S R 2}, i_{P 3} M_{O S R 3}\right]^{T}$ - wektor zredukowanych oporów ruchu śrub.

\section{Kinematyka i dynamika manipulatora}

Widok robota manipulacyjnego przedstawiono na rysunku 2, a schemat kinematyczny na rysunku 3. Przyjęto lokalne układy współrzędnych zgodnie z notacją Denawita-Hartenberga (DH) [7, 8] oraz bazowy układ odniesienia $x y z$. Parametry zestawiono $\mathrm{w}$ tabeli 1 , gdzie zmienne przegubowe to $l_{j}, j=1,2,3$. Ostatni układ odniesienia związano z końcówką roboczą (punkt D).

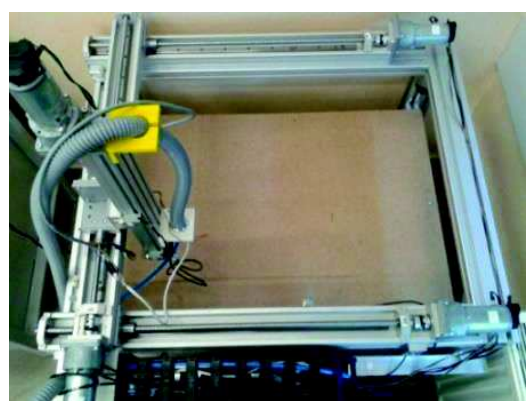

Rys. 2. Widok manipulatora

Fig. 2. The manipulator

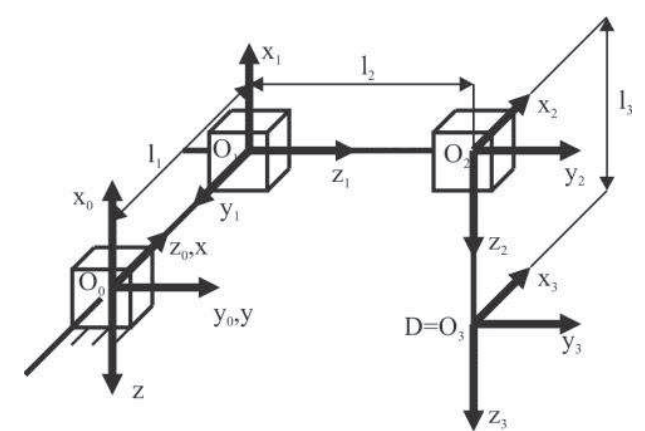

Rys. 3. Schemat kinematyczny manipulatora

Fig. 3. The kinematic diagram of the manipulator

Tabela 1. Parametry manipulatora wg notacji D-H

Table 1. Parameters of the manipulator according to D-H notation

\begin{tabular}{|c|c|c|c|c|}
\hline$j$ & $a_{j}, \mathrm{~m}$ & $\alpha_{j}, \mathrm{rad}$ & $d_{j}, \mathrm{~m}$ & $\theta_{j}, \mathrm{rad}$ \\
\hline 1 & 0 & $3 \pi / 2$ & $l_{1}$ & 0 \\
\hline 2 & 0 & $\pi / 2$ & $l_{2}$ & $3 \pi / 2$ \\
\hline 3 & 0 & 0 & $l_{3}$ & 0 \\
\hline
\end{tabular}

Uwzględniając dodatkowo rotację układu $x_{0} y_{0} z_{0}$ względem bazowego $x y z$ określono macierz transformacji układu 3 do bazowego jako: 


$$
\mathbf{A}=\left[\begin{array}{cccc}
1 & 0 & 0 & l_{1}(t) \\
0 & 1 & 0 & l_{2}(t) \\
0 & 0 & 1 & l_{3}(t) \\
0 & 0 & 0 & 1
\end{array}\right]
$$

Z powyższego wzoru wynika, że orientacja końcówki roboczej jest stała, a zmienne przegubowe $l_{j}$, które są funkcjami czasu, są wprost współrzędnymi kartezjańskimi końcówki w przestrzeni roboczej, tzn.:

$$
\mathbf{p}_{D}=\left[\begin{array}{l}
x_{D}(t) \\
y_{D}(t) \\
z_{D}(t)
\end{array}\right]=\left[\begin{array}{l}
l_{1}(t) \\
l_{2}(t) \\
l_{3}(t)
\end{array}\right]
$$

gdzie: $\mathbf{p}_{D}$ - wektor współrzędnych kartezjańskich końcówki manipulatora,

$$
x_{D}(t), y_{D}(t), z_{D}(t) \text { - współrzędne końcówki manipulatora. }
$$

Natomiast prędkość końcówki roboczej to:

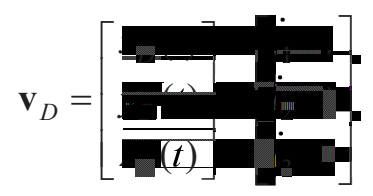

W celu wyprowadzenia dynamicznych równań ruchu robota $[2,7,10]$ zastosowano równania Lagrange'a II rodzaju, których postać dana jest wzorem:

$$
\frac{d}{d t}\left(\frac{\partial E}{\partial \overline{\boldsymbol{q}_{\bar{j}}}}\right)-\frac{\partial E}{\partial q_{j}}=Q_{j}
$$

gdzie: $E$ - energia kinetyczna analizowanego układu,

$q_{j}$ - współrzędna uogólniona,

$Q_{j}$ - siła uogólniona odpowiadająca współrzędnej uogólnionej.

Energia kinetyczna układu to:

$$
E=\frac{1}{2} \sum_{j=1}^{3} m_{j} v_{j}^{2}
$$

gdzie: $m_{j}-$ masa $j$-tego członu,

$v_{j}$ - prędkość środka masy $j$-tego członu,

$Q_{j}$ - siła uogólniona odpowiadająca współrzędnej uogólnionej. 
Prędkości poszczególnych członów to:

$$
\left\{\begin{array}{l}
v_{1}=\dot{1} \\
v_{2}=\sqrt{i_{1}^{2}+\dot{l}_{2}^{2}} \\
v_{3}=\sqrt{i_{1}^{2}+\dot{l}_{2}^{2}+\dot{l}_{3}^{2}}
\end{array}\right.
$$

Założono, że na każdy człon działają następujące siły: siła $P_{j}$ napędzająca człon działająca wzdłuż osi przegubu, siła oporu ruchu wózka po prowadnicy $F_{j}$ oraz ciężar członu $G_{j}$ działający wzdłuż osi z (rys. 4).

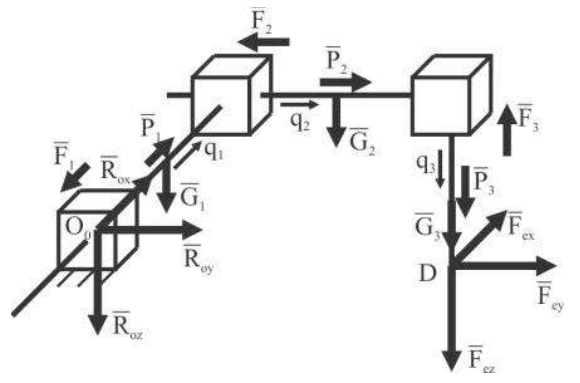

Rys. 4. Układ sił działający na manipulator

Fig. 4. The forces system acting on the manipulator

Ponadto w punkcie D działa na końcówkę roboczą siła zewnętrzna $\mathbf{F}_{e}=\left[F_{e x}, F_{e y}, F_{e z}\right]^{T}$, a w punkcie $\mathrm{O}_{0}$ występują reakcje z ostoją. Zakładając współrzędne uogólnione jako $q_{j}=l_{j}$, wyznaczono siły uogólnione z zastosowaniem zasady prac przygotowanych porównując pracę przygotowaną sił uogólnionych z pracą przygotowaną działającego układu sił i otrzymano

$$
\left\{\begin{array}{l}
Q_{1}=P_{1}-F_{1}+F_{e x} \\
Q_{2}=P_{2}-F_{2}+F_{e y} \\
Q_{3}=P_{3}-F_{3}+F_{e z}+G_{3}
\end{array}\right.
$$

Uwzględniając równania (11)-(13) w (10) zapisano dynamiczne równania ruchu jako:

$$
\left\{\begin{array}{l}
\left(m_{1}+m_{2}+m_{3}\right) \ddot{l}_{1}=P_{1}-F_{1}+F_{e x} \\
\left(m_{2}+m_{3}\right) \ddot{l}_{2}=P_{2}-F_{2}+F_{e y} \\
m_{3} \ddot{l}_{3}=P_{3}-F_{3}+F_{e z}+G_{3}
\end{array}\right.
$$

które wygodnie jest zapisać w postaci macierzowej:

$$
\mathbf{M i}=\mathbf{P}-\mathbf{F}+\mathbf{F}_{e}+\mathbf{G}
$$


gdzie: $\mathbf{M}=\operatorname{diag}\left\{m_{1}+m_{2}+m_{3}, m_{2}+m_{3}, m_{3}\right\}-$ macierz bezwładności,

$\mathbf{I}=\left[l_{1}, l_{2}, l_{3}\right]^{T}-$ wektor przemieszczeń uogólnionych,

$\mathbf{P}=\left[P_{1}, P_{2}, P_{3}\right]^{T}-$ wektor sił napędzających,

$\mathbf{F}=\left[F_{1}, F_{2}, F_{3}\right]^{T}-$ wektor sił oporów ruchu,

$\mathbf{G}=\left[0,0, G_{3}\right]^{T}-$ wektor sił grawitacji.

Uwzględniając opis dynamiki układu (15) w równaniu (6), otrzymano:

$$
\mathbf{J}_{z} \ddot{\mathbf{q}}_{S}+\mathbf{R}-\mathbf{i} \mathbf{G}=\mathbf{K} \mathbf{i}_{W}+\mathbf{i} \mathbf{F}_{e}
$$

gdzie: $\mathbf{J}_{z}=\mathbf{J}+\mathbf{i} \mathbf{M i}-$ macierz bezwładności członów robota,

$\mathbf{R}=\mathbf{B} \dot{\mathbf{q}}_{S}+\mathbf{F}_{S R}+\mathbf{i F}-$ wektor sumarycznych oporów ruchu.

Człon $\mathbf{R}$ uwzględniający opory ruchu, można modelować w różnorodny sposób. Powszechnie stosowanym modelem tarcia jest kombinacja modeli tarcia wiskotycznego i suchego. Model taki uzyskano zakładając elementy w wektorze $\mathbf{F}_{S R} \mathrm{~W}$ postaci:

$$
M_{O S R j}=B_{S R v j} \dot{q}_{S R j}+B_{S R c j} \operatorname{sgn}\left(\dot{q}_{S R j}\right)
$$

oraz elementy w wektorze oporów ruchu wózków $\mathbf{F}$ jako

$$
F_{j}=B_{W v j} i_{j}+B_{W c j} \operatorname{sgn}\left(i_{j}\right)
$$

gdzie: $B_{S R v j}$ i $B_{W v j}$ - współczynniki oporu wiskotycznego ruchu śruby i wózka,

$B_{S R c j}$ i $B_{W c j}$ - współczynniki oporu suchego ruchu śruby i wózka.

Grupując współczynniki występujące w równaniach ruchu otrzymano ostatecznie model dynamiki manipulatora w postaci równania (16) gdzie:

$$
\begin{aligned}
\mathbf{J}_{z} & =\left[\begin{array}{ccc}
p_{1} & 0 & 0 \\
0 & p_{2} & 0 \\
0 & 0 & p_{3}
\end{array}\right] \\
\mathbf{R} & =\left[\begin{array}{c}
p_{4} \dot{q}_{S 1} \\
p_{5} \dot{q}_{S 2} \\
p_{6} \dot{\boldsymbol{q}}_{S 3}
\end{array}\right]+\left[\begin{array}{l}
p_{7} \operatorname{sgn}\left(\dot{q}_{\mathbf{s}}\right) \\
p_{8} \operatorname{sgn}\left(\dot{q}_{S \mathbf{s}}\right) \\
p_{9} \operatorname{sgn}\left(\dot{q}_{\mathbf{s}}\right)
\end{array}\right], \\
\mathbf{G} & =\left[\begin{array}{c}
0 \\
0 \\
p_{10}
\end{array}\right]
\end{aligned}
$$

oraz: 


$$
\left\{\begin{array}{l}
p_{1}=J_{1}+\left(m_{1}+m_{2}+m_{3}\right) i_{P 1}^{2} i_{S R 1}^{2} \\
p_{2}=J_{2}+\left(m_{2}+m_{3}\right) i_{P 2}^{2} i_{S R 2}^{2} \\
p_{3}=J_{3}+m_{3} i_{P 3}^{2} i_{S R 3}^{2} \\
p_{4}=B_{S 1}+B_{S R v 1} i_{P 1}^{2}+B_{W v 1} i_{P 1}^{2} i_{S R 1}^{2} \\
p_{5}=B_{S 2}+B_{S R v 2} i_{P 2}^{2}+B_{W v 2} i_{P 2}^{2} i_{S R 2}^{2} \\
p_{6}=B_{S 3}+B_{S R v 3} i_{P 3}^{2}+B_{W v 3} i_{P 3}^{2} i_{S R 3}^{2} \\
p_{7}=B_{S R c 1} i_{p 1}+B_{W c 1} i_{p 1} i_{S R 1} \\
p_{8}=B_{S R c 2} i_{p 2}+B_{W c 2} i_{p 2} i_{S R 2} \\
p_{9}=B_{S R c 3} i_{p 3}+B_{W c 3} i_{p 3} i_{S R 3} \\
p_{10}=m_{3} g
\end{array}\right.
$$

Wartości parametrów modelu matematycznego zebrano w tabeli 2.

Tabela 2. Parametry manipulatora

Table 2. Parameters of the manipulator

\begin{tabular}{|c|c|c|}
\hline Parametr & Jednostka & Wartość \\
\hline$p_{1}$ & \multirow{3}{*}{$\mathrm{kgm}^{2} / \mathrm{s}$} & $1.4236 \cdot 10^{-5}$ \\
\hline$p_{2}$ & & $7.0957 \cdot 10^{-6}$ \\
\hline$p_{3}$ & & $7.0957 \cdot 10^{-6}$ \\
\hline$p_{4}$ & \multirow{3}{*}{$\mathrm{kgm}^{2} / \mathrm{s}$} & $2.8156 \cdot 10^{-5}$ \\
\hline$p_{5}$ & & $1.4078 \cdot 10^{-5}$ \\
\hline$p_{6}$ & & $1.4078 \cdot 10^{-5}$ \\
\hline$p_{7}$ & \multirow{3}{*}{$\mathrm{Nm}$} & 0.0159 \\
\hline$p_{8}$ & & 0.0079 \\
\hline$p_{9}$ & & 0.0079 \\
\hline$p_{10}$ & $\mathrm{~N}$ & 49.0500 \\
\hline
\end{tabular}

\section{Właściwości strukturalne modelu matematycznego}

W tym rozdziale zaprezentowane zostaną właściwości strukturalne modelu matematycznego manipulatora [2, 11], których znajomość jest konieczna w syntezie algorytmów sterowania manipulatorami. Zostanie przeanalizowany model matematyczny określony równaniem (16). Jest to model matematyczny odpowiadający przypadkowi manipulatora sztywnego.

Właściwość 1. Macierz bezwładności $\mathbf{J}_{z}$ jest symetryczna, dodatnio określona $\mathrm{i}$ spełnia ograniczenie:

$$
\sigma_{\min }\left(\mathbf{J}_{z}\right) \mathbf{I} \leq \mathbf{J}_{z} \leq \sigma_{\max }\left(\mathbf{J}_{z}\right) \mathbf{I}
$$


gdzie: $\mathbf{I} \in R^{3 \times 3}-$ macierz jednostkowa,

$\sigma_{\min }\left(\mathbf{J}_{z}\right)$-minimalna ściśle dodatnia wartość własna macierzy $\mathbf{J}_{z}$,

$\sigma_{\max }\left(\mathbf{J}_{z}\right)$-maksymalna ściśle dodatnia wartość własna macierzy $\mathbf{J}_{z}$.

Wlaściwość 2. Równanie dynamiki manipulatora jest liniowe względem parametrów, co zapisano:

$\mathbf{Y}(\mathbf{q}, \dot{\mathbf{q}}, \ddot{\mathbf{q}}) \mathbf{p}=\mathbf{K} \mathbf{i}_{W}+\mathbf{i} \mathbf{F}_{e}$

gdzie: $\mathbf{Y}(\mathbf{q}, \dot{\mathbf{q}}, \ddot{\mathbf{q}})=R^{3 \mathbf{m} 10}$ - macierz regresji,

$\mathbf{p}=\left[p_{1}, p_{2}, p_{3}, p_{4}, p_{5}, p_{6}, p_{7}, p_{8}, p_{9}, p_{10}\right]^{T}-$ wektor parametrów modelu.

Macierz regresji ma postać:

$\mathbf{Y}(\mathbf{q}, \dot{\mathbf{q}}, \ddot{\mathbf{q}})$

$\left[\begin{array}{c|c|c|c|c|c|c|c|c|c}\ddot{q}_{\mathbf{a}} & 0 & 0 & \dot{q}_{S 1} & 0 & 0 & \operatorname{sgn}\left(\dot{q}_{\mathbf{S}}\right) & 0 & 0 & 0 \\ \hline 0 & \ddot{q}_{S 2} & 0 & 0 & \dot{q}_{S 2} & 0 & 0 & \operatorname{sgn}\left(\dot{q}_{S \amalg}\right) & 0 & 0 \\ \hline 0 & 0 & \ddot{q}_{S 3} & 0 & 0 & \dot{q}_{S 3} & 0 & 0 & \operatorname{sgn}\left(\dot{q}_{S \amalg}\right) & 1\end{array}\right]$

Wlaściwość 3. Wektor iG spełnia zależność:

$$
\|\mathbf{i G}\|=i_{p 3} i_{S R 3} p_{10},
$$

Właściwość 4. Wektor $\mathbf{R}$ spełnia ograniczenie:

$$
\|\mathbf{R}\| \leq r_{1}\left\|\mathbf{m}_{S}\right\|+r_{2} \sqrt{\left|\dot{\phi}_{S 1}\right|+\left|\dot{q}_{S 2}\right|+\left|\dot{q}_{S 3}\right|}+\mathbf{r}_{3}
$$

gdzie: $r_{1}=\max \left\{p_{4}, p_{5}, p_{6}\right\}$,

$$
\begin{aligned}
& r_{2}=\max \left\{\sqrt{2 p_{4} p_{7}}, \sqrt{2 p_{5} p_{8}}, \sqrt{2 p_{6} p_{9}}\right\}, \\
& r_{3}=\sqrt{p_{7}^{2}+p_{8}^{2}+p_{9}^{2}} .
\end{aligned}
$$

Właściwość 5. Macierz przełożeń przekładni i jest stała, diagonalna i dodatnio określona.

Właściwość 6. Macierz stałych momentowych silników $\mathbf{K}$ jest stała, diagonalna i dodatnio określona. 


\section{Podsumowanie}

W pracy zaprezentowano metodykę modelowania manipulatora kartezjańskiego z zastosowaniem równań Lagrange'a drugiego rodzaju i uwzględnieniem dynamiki napędów. W modelu matematycznym uwzględniono jedynie najważniejsze zjawiska fizyczne występujące podczas ruchu członów manipulatora, tzn. zjawisko bezwładności, opory ruchu, wpływ sił ciężkości oraz interakcję końcówki roboczej ze środowiskiem. Pominięto natomiast takie zjawiska jak np. deformacje członów, deformacje i luzy w układzie przeniesienia napędu czy drgania mechaniczne. Dzięki takiemu podejściu uzyskany model jest liniowy względem parametrów i wykazuje typowe właściwości strukturalne modeli matematycznych manipulatorów sztywnych [2]. Może być zastosowany w syntezie układu sterowania robotem.

\section{Literatura}

[1] Burghardt A. Giergiel J.: Modelling of mobile wheeled robot with dynamic drive compliance, Modelling Optimization Phys. Systems, 9 (2010) 7-12.

[2] De Wit C.C., Siciliano B., Bastin G.: Theory of Robot Control, Springer, London 1996.

[3] Elkady A.Y., Hanna S. N., Elkobrosy G. A.: On the modeling and control of the Cartesian parallel manipulator, in: Advances in Computer and Information Sciences and Engineering, Sobh T. (ed.), books.google.com 2008, pp. 90-96.

[4] Kim H.-S., Tsai L.-W.: Evaluation of a Cartesian parallel manipulator, in: Advances in Robot Kinematics, Lenarčič J., Thomas F. (eds.), Kluwer Academic Publishers, Norwell 2002.

[5] Maeda G. J., Sato K.: Practical control method for ultra-precision positioning using a ballscrew mechanism, Precision Eng., 32 (2008) 309-318.

[6] Pratiher B., Bhowmick S.: Nonlinear dynamic analysis of a Cartesian manipulator carrying an end effector placed at an intermediate position, Nonlinear Dynamics, 69 (2012) 539-553.

[7] Spong M.W., Vidyasagar M.: Dynamika i sterowanie robotów, WNT,Warszawa 1997.

[8] Tchoń K., Mazur A., Dulęba I., Hossa R., Muszyński R.: Manipulatory i roboty mobilne: modele, planowanie ruchu i sterowanie, AOW PLJ, Warszawa 2000.

[9] Yen P.-L., Lai C.-C.: Dynamic modeling and control of a 3-DOF Cartesian parallel manipulator, Mechatronics, 19 (2009) 390-398.

[10] Żylski W., Gierlak P.: Modelowanie ruchu wybranego manipulatora, Acta Mech. Automatica, 4 (2010) 112-119.

[11] Żylski W., Gierlak P.: Sterowanie ruchem nadążnym robotów manipulacyjnych, OW PRz, Rzeszów 2014. 


\section{THE MATHEMATICAL MODEL OF THE CARTESIAN ROBOTIC} MANIPULATOR OF OWN DESIGN

\section{S u m m a r y}

In the paper, the mathematical model of the robotic manipulator of own design is presented. The Cartesian manipulator has three degrees of freedom. The mathematical description of kinematics and dynamics is formulated. The Denavit-Hartenberg notation for kinematics description is used. The dynamical equations of motion of the manipulator are obtained by using Lagrange's equations of the second kind. In the manipulator's dynamics description, the dynamics of the drives is taken into account. An analysis of the structural properties of mathematical model is presented. Proved properties are useful in the synthesis of control algorithms.

Keywords: the Cartesian manipulator, model of manipulator, manipulator kinematics, manipulator dynamics, structural properties of model

DOI: $10.7862 / \mathrm{rm} .2016 .10$

Otrzymano/received: $28.04 .2016 r$.

Zaakceptowano/accepted: 9.06.2016 r. 